\title{
Phytochemicals in Edible Wild Mushrooms From Selected Areas in Kenya
}

\author{
T. W. Wandati ${ }^{1}$, G. M. Kenji ${ }^{1} \&$ J. M. Onguso ${ }^{2}$ \\ ${ }^{1}$ Department of Food Science, Jomo Kenyatta University of Agriculture and Technology Nairobi, Kenya \\ ${ }^{2}$ Institute of Biotechnology Research, Jomo Kenyatta University of Agriculture and Technology Nairobi, Kenya \\ Correspondence: T. W. Wandati, Department of Food Science, Jomo Kenyatta University of Agriculture and \\ Technology, P. O. Box 62000-00200, Nairobi, Kenya. E-mail: wan.wanda@yahoo.com/twandati@gmail.com
}

\author{
Received: March 1, 2013 Accepted: May 22, 2013 Online Published: May 27, 2013 \\ doi:10.5539/jfr.v2n3p137 URL: http://dx.doi.org/10.5539/jfr.v2n3p137
}

\begin{abstract}
Mushrooms have been used as food for centuries all over the world because of their characteristic soft texture and mild flavor. They are documented as being good source of nutrients and bioactive compounds that are beneficial to the human body (Chang, 2011). While the exotic varieties have been extensively analyzed, local edible wild mushrooms have not and yet they are consumed by communities living near the forests. This research aimed at screening and determination of phytochemicals compounds in wild edible mushroom found in selected areas in Kenya Two commercially grown mushrooms, oyster (Pleurotus florida) and button (Agaricus bisporus), and ten edible wild mushrooms species were collected from different locations of the country. They were analyzed for total polyphenols, flavonoids and radical scavenging activity using standard methods. All the analysis was done in triplicate. Phytochemical screening showed presence of saponins, polyphenols and terpenoids. Total polyphenols values obtained ranged between 210-1614 mg Gallic Acid equivalent (GAE)/100g, dry weight basis (dwb) and flavonoids 214-1695 $\mathrm{mg}$ Quercetin Equivalent (QE)/100 g dwb. Total polyphenols $\left(\mathrm{R}^{2}=0.82, \mathrm{P} \leq 0.05\right)$ and flavonoids values showed a positive correlation with the radical scavenging activity.
\end{abstract}

The results show that cultivated and wild edible mushrooms are rich in health-promoting phytochemical compounds.

Keywords: mushrooms, phenolic compounds, flavonoids, radical scavenging activity

\section{Introduction}

Mushroom has been defined as 'a macro-fungus with a distinctive fruiting body, which can be hypogenous or epigeous, large enough to be seen with the naked eye and to be picked by hand (Chang \& Miles, 1989) They are documented as being rich in proteins, minerals, vitamins while they are low in lipids (Pathak et al., 1997).

Documented literature indicates that mushrooms have photochemicals and other compounds which are strong antioxidants (Fang et al., 2002; Liu, 2004). Phenolic compounds, alkaloids, saponins, flavonoids, tannins, sterols, triterpenes, coumarins and cyanogenic glycosides have been detected in wild mushrooms analyzed in Sudan and in Nigeria (Adebayo et al., 2012; Egwim et al., 2011; Ehssan \& Saadabi, 2012).

The compounds seem to mop the free radicals generated in the normal natural metabolism of aerobic cells, mostly in the form of reactive oxygen species (ROS). These include superoxide $\left(\mathrm{O}_{2}^{-}\right)$and hydroxyl $\left(\mathrm{OH}^{-}\right)$ radicals among several others. Exogenous sources of free radicals include tobacco smoke, ionizing radiation, certain pollutants, organic solvents and pesticides (Barja, 2004). Once in circulation, most of the free radicals are neutralized by cellular antioxidant defense enzymes e.g. Superoxide dismutase (SOD) or catalase (CAT). Non-enzymatic molecules like ascorbic acid and carotenoids are reported to be present in mushrooms and they also act as antioxidants (Fang et al., 2002; Isabel et al., 2004). Maintenance of equilibrium between free radicals production and antioxidant defenses is an essential condition for normal organism functioning (Hollman \& Arts, 2000). The disequilibrium, excess free radicals in the system, is known as oxidative stress. It interferes with cell integrity hence normal functioning is altered leading to many stress-related diseases like cancers and diabetes.

Mushroom nutriceuticals describe a new class of compounds extractable from either the mycelium or fruit body of mushrooms and embodies both their nutritional and medicinal features. They are consumed as a dietary supplement which has potential therapeutic applications (Chang \& Miles, 1989). Mushroom Nutraceuticals are 
enriched food materials which are used for Maintenance of healthy diet. These are part of a meal (Chang \& Miles, 1989; Shiuan, 2004). Infusion of mushrooms has been used to prevent beriberi. In addition, the decoction has been used for the treatment of abscesses and wounds (Yu et al., 2009).

\section{Materials and Methods}

\subsection{Materials}

Mushrooms used in this research comprised of wild mushrooms (Figure 1) collected from natural habitat and included 7 species from Arabuko Sokoke, one species from Aberdares and Mt Elgon forests, 2 species from Kisumu and Kakamega counties. Two cultivated species; oyster (Preurotus florida) and button (Agaricus biporus) were included for comparison. To determine the effect of maturity and mushroom parts on phytochemicals, oyster was segregated into young and mature fruit bodies while oruka was segregated into caps (pilei) and stipes Samples of fresh wild mushrooms were taken to the Museums of Kenya, Botany/Herbarium department for scientific identification which is still in progress. Consequently, local mushroom names will be used in this report for uniformity.
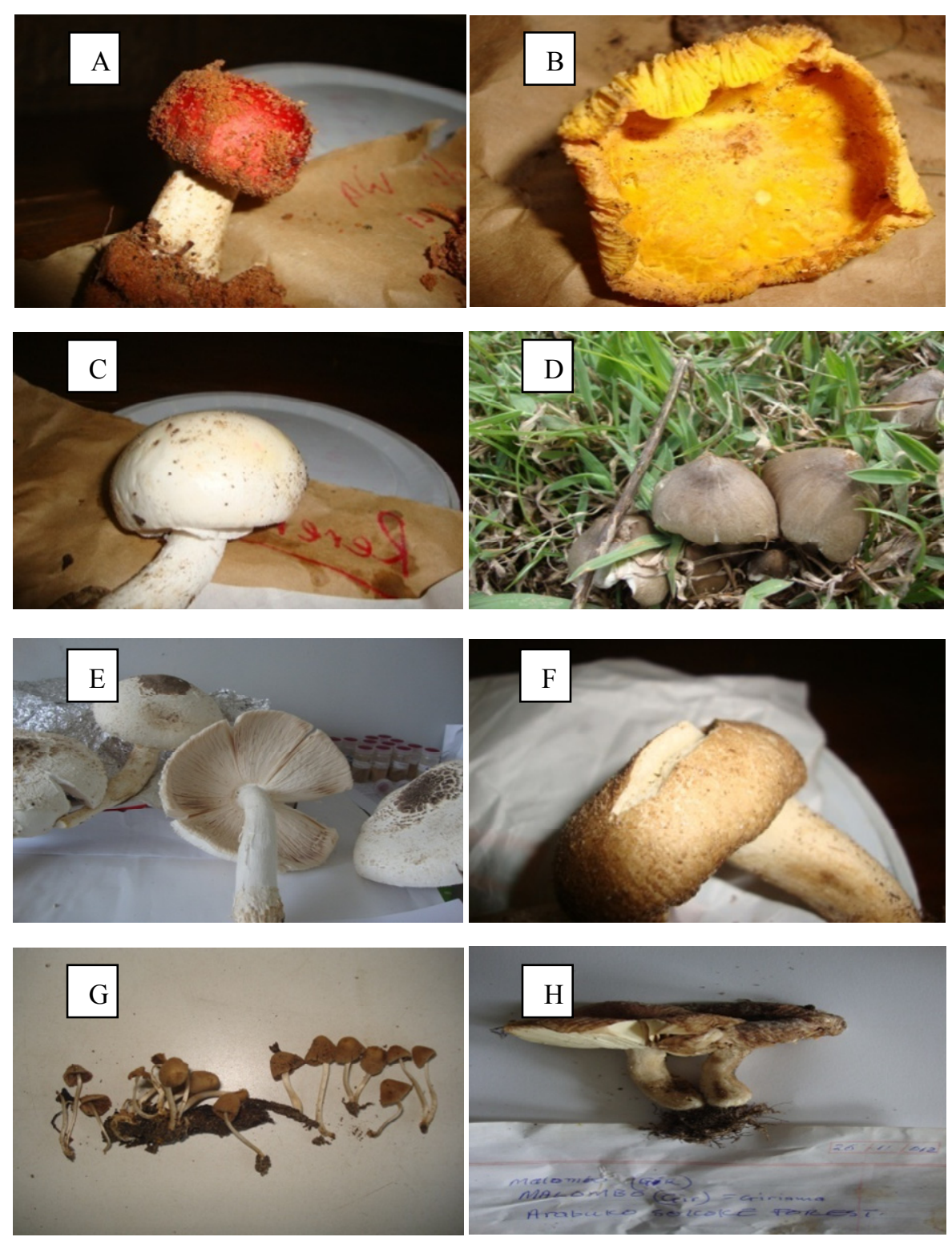

Figure 1. Some of the wild mushrooms collected: A Mkundu wa nyani; B, Masikiro meruhe; C, Rerema; D, Mariondonic/makunu ma mutitu; E, Oruka; F, Joga muhama; G, Kadzodzo; H, Malombo 


\subsection{Sample Preparation}

At the university, Jomo Kenyatta University of Agriculture and Technology (JKUAT), they gently brushed off dirt and were all dried at $70^{\circ} \mathrm{C}$, ground using laboratory mill. The Milled mushroom was put in labeled air-tight bottles and stored at $4{ }^{\circ} \mathrm{C}$.

\subsection{Preparation of Mushroom Extracts}

Extraction, screening and quantification was done according to the method described by Harbone (1998) with minor modifications Known weight of the dried mushroom powder was mixed with $100 \mathrm{ml}$ ethanol in a conical flask. The content was put on a shaker for 24 hours at room temperature. The liquid part was decanted and stored at $4^{\circ} \mathrm{C}$. The solid was re-suspended in ethanol and procedure repeated. The liquid was then combined, filtered using whatman paper no. 4 . The filtrate was concentrated in vacuum evaporator to $10 \mathrm{ml}$. This was put in sample bottles and stored at $4{ }^{\circ} \mathrm{C}$ to await further analysis. Similarly, known weights of mushroom powder were mixed with hot water $\left(50^{\circ} \mathrm{C}\right)$, put on a shaker for 24 hours. The rest of the procedure was as described.

\subsection{Quick Tests for Phytochemicals}

Ethanolic and water extracts were subjected to preliminary phytochemical screening for the identification of various classes of active chemical constituents using standard methods (References).

\subsubsection{Quick Test for Saponins' Presence}

Foam test: To $1 \mathrm{ml}$ of the extracts $5 \mathrm{ml}$ distilled water was added and shaken vigorously. Formation of foam indicated presence of saponins.

\subsubsection{Quick Test for Total Polyphenols}

Ferric Chloride test: To $1 \mathrm{ml}$ of the extract, $2 \mathrm{ml}$ of distilled water, 3 drops of $10 \%$ aqueous ferric chloride $\left(\mathrm{FeCl}_{3}\right)$ and 3 drops of potassium ferrocyanide were added. Formation of blue or green color showed the presence of polyphenols.

\subsubsection{Quick Test for Anthraquinones}

Weighed mushroom powder, $0.5 \mathrm{~g}$, was boiled in $10 \%$ hydrochloric acid and filtered hot. To this, $2 \mathrm{ml}$ chloroform and $10 \%$ ammonia solution each were added .Formation of pink color in the aqueous layer indicated presence of anthraquinones.

\subsubsection{Quick Test for Terpenoids}

Water extract, $5 \mathrm{ml}$, was mixed with $2 \mathrm{ml}$ chloroform followed by sulfuric acid along the tube wall. Formation of brown color at interface was a positive indicator.

\subsubsection{Quick Test for Tannins}

To $3 \mathrm{ml}$ ethanolic extract was added $3 \mathrm{ml} 10 \%$ ferric chloride $\left(\mathrm{FeCl}_{3}\right)$. Formation of blue/black color was a positive indicator.

\subsubsection{Quick Test for Alkaloids}

On silica gel-coated plates, $10 \mu \mathrm{l}$ extract was spotted equidistance from each other and eluted with methanol-sulfuric acid solution. The dried plates were sprayed with Dragendr off reagent. Formation of red-brown color was positive indicator.

\subsection{Determination of Total Polyphenols}

Phenolic compounds in the mushroom extracts were estimated by a colorimetric assay, based on standard procedures described by Harbone (1998) with minor modifications.

To $5 \mathrm{ml}$ distilled water was added $0.5 \mathrm{ml}$ Folin Ciocalteu's reagent. After $3 \mathrm{~min}, 1 \mathrm{ml}$ 7.5\% sodium carbonate solution, $1 \mathrm{ml}$ extract were added to the mixture and made to $10 \mathrm{ml}$ with distilled water. The mixture was kept in water bath maintained at $50^{\circ} \mathrm{C}$ for 16 minutes. UV Visible spectrophotometer (UV-Vis Shimadzu) was used to read the absorbance at $765 \mathrm{~nm}$. Gallic acid was prepared in different concentrations and the absorbance equally read at $765 \mathrm{~nm}$. The values obtained were used to generate the standard curve against which polyphenols in the mushrooms were calculated and expressed as Gallic acid equivalents (GAEs) per $100 \mathrm{~g}$ dwb.

\subsection{Determination of Flavonoids as Quecetin Equivalent}

Flavonoids contents in the extracts were determined by standard colorimetric method with minor modifications. To $1 \mathrm{ml}$ mushroom extract was added $0.3 \mathrm{ml} \%$ sodium nitrite; $4 \mathrm{ml}$ distilled water and held for 5 minutes. To the mixture $0.3 \mathrm{ml} 10 \%$ aluminium chloride was added and held for 6 minutes. Finally $2 \mathrm{ml} 1 \mathrm{M}$ sodium 
hydroxide was added and the content made to $10 \mathrm{ml}$ with distilled water. Using UV spectrophotometer, (UV-Vis) the intensity of pink color was measured at $415 \mathrm{~nm}$. Pure quercetin was prepared in different concentrations and absorbance read at same wavelength. The readings were used to make standard curve against which flavonoids in the sample were calculated and expressed as $\mathrm{mg}$ of quercetin equivalents $(\mathrm{QE}) / 100 \mathrm{~g}$ dwb.

\subsection{Determination of Radical Scavenging Activity (RAS) Using DPPH}

The radical scavenging activities of the mushroom extracts against 2, 2-Diphenyl-1-picryl hydrazyl radical were determined by UV visible spectrophotometer, UV-Vis-SDD-10AV SHIMADZU, at $517 \mathrm{~nm}$. Radical scavenging activity was measured using standard procedures. The following concentrations of the extracts were prepared, $0.05,0.1,0.5,1.0,2.0$ and $5 \mathrm{mg} / \mathrm{ml}$ in ethanol. Ascorbic acid was used as the antioxidant standard at concentrations of $0.02,0.05,0.1,0.2,0.5$ and $0.75 \mathrm{mg} / \mathrm{ml}$.

To $1 \mathrm{ml}$ of the extract in a test tube $3 \mathrm{ml}$ ethanol was added followed by $0.5 \mathrm{ml} 1 \mathrm{mM}$ DPPH in ethanol. Incubation was done for 5 minutes. A blank solution was prepared containing the same amount of ethanol and DPPH. The absorbance of the blank was read at $517 \mathrm{~nm}$ and a standard curve generated using the values. The absorbance of solutions with extract was similarly read at $517 \mathrm{~nm}$.

The radical scavenging activity (RSA) was calculated as a percentage of DPPH discoloration using the equation:

$\% \mathrm{RSA}=[(\mathrm{ADPPH}-\mathrm{AS}) / \mathrm{ADPPH}] 100$, where AS is the absorbance of the solution when the sample extract has been added at a particular level, and ADPPH is the absorbance of the DPPH solution.

The extract concentration providing $50 \%$ inhibition $\left(\mathrm{EC}_{50}\right)$ was calculated from the graph.

\subsection{Statistical Analysis}

Results are given as mean of triplicate \pm SD. Correlation coefficient between total polyphenols and radical scavenging activity was done by regression using Genstat statistical software version 14 .

\section{Results and Discussion}

\subsection{Mushrooms Collected}

Result of the mushroom collected and analyzed is shown in Table 1.

Collection is normally done early in the morning. A major problem encountered in collection is competition with wild animals like the baboons. It is common to find they started earlier and have eaten them, so one comes back empty handed. Encounter with dangerous animals like elephants is a reality which makes it very risky to the communities that would benefit from this freely available food. Entry to the forest is therefore highly restricted by Kenya Wildlife Service (KWS). The volume picked is therefore very low and no conservation is done. Where collection is from disturbed land e.g. Kakamega and Kisumu, drying is done and it is possible to buy dry mushroom in far off places.

Table 1. Mushrooms collected and analyzed

\begin{tabular}{llll}
\hline Botanical name & $\begin{array}{l}\text { Common/Local name } \\
\text { (community) }\end{array}$ & Region & Habitat \\
\hline Agaricus bisporus & button/makunu (kikuyu) & Central & Commercially grown \\
Preurotus florida & Oyster/Makunu (kikuyu) & Central & Commercially grown \\
Termitomyces $\boldsymbol{s} \boldsymbol{p}$ & Makunu ma mutitu(kikuyu) & Central & Grows on farms/ forest/ anywhere \\
Termitomyces $\boldsymbol{s} \boldsymbol{p}$ & Mariondonik (Sabaot) & Rift valley & Grows on farms/ forest/ anywhere \\
- & Olando (Dholuo) & Nyanza & Grows on farms \\
- & Obulando (Luhya) & Western & Grows on in farms \\
Termitomyces sp & Oruka (Dholuo) & Nyanza & Grows on ant-hills \\
- & Joga muhama (Giriama) & Coast & Grows on disturbed land. \\
& Joga misinga (wadtha) & & Grows on ant -hills \\
Termitomyces $\boldsymbol{s} \boldsymbol{p}$ & Joga utuwe (Giriama) & Coast & Mixed \& Brachystegia forests \\
\hline
\end{tabular}




\begin{tabular}{llll}
\hline Russula Compressa & Mkundu wa nyani (Giriama) & Coast & Brachystegia forests \\
- & Joga kadzonzo (Giriama) & Coast & Mixed \& Brachystegia forests \\
Amanita zambiana & Rerema (Giriama) & Coast & Mixed \& Brachystegia forests \\
- & Masikiro meruhe (Giriama) & Coast & Mixed \& Brachystegia forests \\
\hline
\end{tabular}

- Name not identified.

Key-Mixed forest is composed of Afzelia quanzensis, Manikara sansibarensis, Hymenaea verrucosa. Trees;

Brachystegia forest is composed of Brachystegia speciformis, Manikara sansibarensis and Hymenaea verrucosa and Patches of grass present. ASF: Arabuko Sokoke Forest in Kenyan coast;

Olando of Kisumu same species as Obulando of Kakamega;

Makunu ma mutitu of Aberdares =same species with mariondonik of Mt Elgon.

\subsection{Quick Assays for Presence of Phytochemical Compounds}

The results of phytochemical screening are given in Table 2. The screening indicated presence of saponins, polyphenols and terpenoids. Alkaloids, tannins and anthraquinons were absent in all the species. The Phenolic compounds include different subclasses (flavonoids, phenolic acids, stilbenes, lignans, tannins, oxidized polyphenols) that display a large diversity of structures (Nijveldt, 2001).

The compound detected will depend on the method used, the $\mathrm{pH}$ and the interaction with other compounds. As a result it is not possible to conclude that those that were absent would not be detected using different reagents or methods.

Saponins comprise a large family of structurally related compounds containing a steroid or triterpernoid aglycone. They are reported to have a wide range of pharmacological properties that exert various benefits, such as anti-inflammatory and anti-diabetic properties (Lee et al., 2012).

Terpenoids (isoprenoids) are secondary metabolites with molecular structures containing carbon backbones made up of isoprene. The compounds have been reported to show a wide range of pharmacological benefits that include anti-malarial, anti-inflammatory and anti-cancer among others (Beattie, 2011; Roslin \& Annular, 2011).

Table 2. Phytochemical compounds detected in the mushrooms

\begin{tabular}{lllllll}
\hline Mushroom & Saponins & Polyphenols & Alkaloids & Tannins & Terpenoids & Anthra-quinones \\
\hline A bisporus & +++ & + & - & - & + & - \\
Pflorida & ++ & + & - & - & + & - \\
Makunu-ma mutitu & + & + & - & - & + & - \\
Mariondonik & + & + & - & - & + & - \\
Obulando & + & + & - & - & + & - \\
Olando & ++ & + & - & - & + & - \\
Oruka & +++ & + & - & - & + & - \\
Joga Muhama & + & + & - & - & + & - \\
Joga utuwe & ++ & + & - & - & + & - \\
Malombo & +++ & + & - & - & + & - \\
Mkundu wa nyani & +++ & + & - & - & + & - \\
Joga kadzonzo & ++ & + & - & - & + & - \\
Rerema & +++ & + & - & - & + & - \\
Masikiro maruhe & +++ & + & - & - & + & - \\
\hline+
\end{tabular}

$+=$ Presence; $++=$ increasing concentration; - = absence;

Olando of Kisumu same species as Obulando of Kakamega;

Makunu ma mutitu of Aberdares =same species with mariondonik of Mt Elgon. 


\subsection{Polyphenols, Flavonoids and Radical Scavenging Activity Values Are Shown in Table 3}

The figures obtained for polyphenols range between 210-1614 mg GAE/100g, dwb. Flavonoids values obtained are 214-1695 $\mathrm{mg} \mathrm{QE} / 100 \mathrm{~g}$ and the RSA values obtained ranged between 58.07-458.01

The total polyphenols content show a positive correlation with flavonoids, high polyphenols accompanied by high flavonoids although not in direct proportionality $(\mathrm{P} \leq 0.05)$. The levels of these compounds are influenced by species, substrate on which mushrooms grew, maturity and the part of the mushroom analyzed (Oboh \& Shodehinde, 2009). High levels of flavonoids were accompanied by high RSA (low value). The radical scavenging activity of phenolic compounds has been correlated to their chemical structures (Nijveldt, 2001). RSA is also influenced by other factors, such as presence of other H-donating groups like $-\mathrm{NH}$ or $-\mathrm{SH}$. Other compounds which have RSA include ascorbic acid, tocopherols, and carotenoids. All these are reported to be present in mushrooms at different levels (Barros et al., 2007). This probably explains why there is no obvious trend that relates levels of TP and TF with RSA. The antioxidant level would therefore be influenced by the nature and levels of compounds elucidated The RSA values obtained range between 58.07-458.01. The reported values are in the same range of 76-1000 mg/100 g dwb in Portuguese wild mushrooms (Barros et al., 2007).

The Young Fruit Bodies (YFB) have higher TP and total flavonoids (TF) than the mature fruit bodies (MFB). This is in conformity to reported figures (Isabel et al., 2004). The author suggested that the compounds in mature stages could be involved in defense mechanism as a result of the aging process; hence reduced content on extraction.

The TP, TF and RSA values are dependent on the part of the mushroom analyzed. This is exemplified by values obtained for oruka cap and stipe. The TP, TF and RSA mean values in cap were 1332.24, 1511.08 and 58.07 respectively. Those for the stipe were 872.57, 648.20 and 59.59 respectively. Similar but lower figures have been reported for total polyphenols in cap 677-1066 and 400-760 for stipe (Isabel et al., 2004). Other reports indicate that polyphenol extracts from the stipes had a significantly $(\mathrm{p}<0.05)$ higher free radical scavenging ability and reducing power than those from the caps (pilei) (Oboh \& Shodehinde, 2009). Whole oruka values were 788.52, 979.6476 .65 for TP, TF and RSA respectively. This indicates that the values obtained for the whole mushroom depend on the proportion of stipe or cap present in the analyzed sample. This research used a whole mushroom.

When all factors that influence the nature and content of phytochemical compounds are considered, the differences are expected. However, although the stipe may have lower TP and TF the RSA may be same or higher than that of cap (Barros et al., 2007). This is the case where values obtained for RSA in cap and stipe is 58.07 and 59.59 respectively. The reason may be that different compounds or compounds with different structures accumulate in stipe but contribute to RSA

All mushrooms from Arabuko sokoke forest exhibited high levels of total polyphenols than the rest from highlands. The flavonoids levels compare well with the mushrooms from other places. However the RSA is not high. This seems to suggest that these compounds are involved in stress-related reactions rather than RSA. This would suggest that the geographic region of coast has influenced the synthesis and bioaccumulation of compounds different from elsewhere. The high temperatures and salt concentration may have influenced production of high levels of polyphenols to cope with environmental stress.

Table 3. Polyphenols, flavonoids and radical scavenging activity values of the mushrooms

\begin{tabular}{llll}
\hline Mushroom & TP GAE (mg/100g) & TF QE (mg/100g) & RSA IC $_{\mathbf{5 0}}(\mathbf{m g} / \mathbf{1 0 0 g})$ \\
\hline Button & $460.42 \pm 1.02$ & $801.34 \pm 0.50$ & $156.83 \pm 0.89$ \\
Oyster-MFB & $675.56 \pm 0.97$ & $890.87 \pm 0.90$ & $61.86 \pm 0.56$ \\
Oyster-YFB & $836.2 \pm 0.59$ & $1129.75 \pm 0.33$ & $62.64 \pm 0.32$ \\
*Makunu ma mutitu & $798.57 \pm 1.03$ & $730.20 \pm 0.55$ & $68.62 \pm 0.48$ \\
*Mariondonik & $728.05 \pm 1.05$ & $798.66 \pm 0.65$ & $70.02 \pm 0.21$ \\
\#Obulando & $432.66 \pm 0.41$ & $740.77 \pm 0.14$ & $185.10 \pm 0.14$ \\
\#Olando & $773.43 \pm 1.54$ & $726.36 \pm 0.20$ & $205.05 \pm 0.05$ \\
Oruka whole & $788.52 \pm 0.45$ & $979.64 \pm 0.60$ & $76.65 \pm 0.57$ \\
Oruka cap & $1332.24 \pm 0.67$ & $1511.08 \pm 0.85$ & $58.07 \pm 0.67$ \\
Oruka stipe & $872.57 \pm 0.90$ & $648.20 \pm 0.79$ & $59.59 \pm 0.60$ \\
\hline
\end{tabular}




\begin{tabular}{llll}
\hline Muhama & $1543.22 \pm 1.22$ & $921.30 \pm 1.02$ & $68.29 \pm 0.45$ \\
Joga utuwe & $1580.08 \pm 0.66$ & $944.55 \pm 0.58$ & $122.45 \pm 0.55$ \\
Malombo & $1080.45 \pm 0.50$ & $528.52 \pm 1.56$ & $112.65 \pm 0.56$ \\
Mkundu wa nyani & $947.95 \pm 0.75$ & $463.50 \pm 0.46$ & $116.25 \pm 0.85$ \\
Joga kadzodzo & $1250.24 \pm 0.56$ & $748.01 \pm 0.55$ & $379.10 \pm 0.70$ \\
Rerema & $1058.05 \pm 0.54$ & $433.10 \pm 0.73$ & $99.15 \pm 0.65$ \\
Masikiro meruhe & $331.54 \pm 0.91$ & $214.15 \pm 0.57$ & $458.01 \pm 0.85$ \\
\hline
\end{tabular}

Values expressed as means, $\mathrm{mg} / 100 \mathrm{~g} \pm \mathrm{SD}$ of triplicates on dry weight basis. Correlation coefficient between $\mathrm{TP}$ and RSA $=0.82$;

$\mathrm{TP}=$ Total polyphenols; $\mathrm{GAE}=$ Gallic Acid Equivalent; $\mathrm{TF}=$ Total flavonoids; $\mathrm{QE}=$ Quercetin Equivalent; RSA $=$ Radical scavenging activity; $\mathrm{IC}_{50}=$ Inhibition concentration for $50 \%$; YFB = Young fruit body; MFB = Mature fruit body;

*Makunu ma mutitu of Aberdares = same species with mariondonik of Mt Elgon; \#Olando of Kisumu same species as Obulando of Kakamega.

\section{Conclusion}

The data obtained from this research clearly show that exotic and wild mushrooms contain phytochemical compounds that are necessary for a healthy body.

\section{Acknowledgement}

We acknowledge Jomo Kenyatta University of Agriculture and Technology for facilitating and funding the research, without which the research work would not have been possible.

\section{References}

Adebayo, E. A., Oloke, J. K., Ayandele, A. A., \& Adegunlola, C. O. (2012). Phytochemical, antioxidant and antimicrobial assay of mushroom metabolite from pleurotuspulmonarius. Journal of Microbiology and Biotechnology Resources, 2(2), 366-374.

Barja, G. (2004). Free radicals and aging. TrendsNeuroscience Journal, 27, 595-600.

Barros, L., Baptista, P., Estevinho, L. M., \& Ferreira, I. (2007). Effect of fruiting body maturity stage on chemical composition and antimicrobial activity of lactariussp. Mushrooms. J. Agric. Food Chemistry, 55, 8766-8771. http://dx.doi.org/10.1021/jf071435+

Chang, S. T. (2011). Training manual on mushroom cultivation technology. United Nations economic and social commission for Asia and the Pacific.

Chang, S. T., \& Miles, P. G. (2011). Recent trends in world production of cultivated edible mushroom. Mushroom Journal, 504, 15-17.

Cheung, L. M, Cheung, P. C. K., \& Oei, V. E. C. (2003). Antioxidant activity and total phenolics of edible

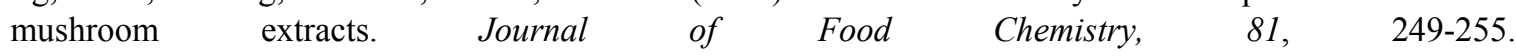
http://dx.doi.org/10.1016/S0308-8146(02)00419-3

Egwim, E. C, Ellen, R. C., \& Egwuche, R. U. (2011). Proximate composition, phytochemical screening and antioxidant activity of ten selected edible mushrooms. American Journal of Food and Nutrition. http://dx.doi.org/10.5251/abjna.2011.1.2.89.94

Ehssan, H. O., \& Saadabi, A. M. (2012). Screening of antimicrobial activity of wild mushrooms from Khartoum State of Sudan. Microbiology Journal, 2, 64-69. http://dx.doi.org/10.3923/mj.2012.64.69

Fang, Y. Z., Yang, S., \& Wu, G. Y. (2002). Free radicals, antioxidants, and nutrition. Nutrition Journal, 18, 872-879. http://dx.doi.org/10.1016/S0899-9007(02)00916-4

Harbone, J. B. (1998). Phytochemical methods: A guide to modern technique of plant analysis (3rd Ed.). New York, NY: Chapman and Hall.

Hollman, P. C. H., \& Arts, I. C. W. (2000). Flavonols, flavones and flavanols -nature, occurrence and dietary burden. Journal Science Food Agriculture, 80, 1081-1093. http://dx.doi.org/10.1002/(SICI)1097-0010(20000515)80:7<1081::AID-JSFA566>3.0.CO;2-G 
Isabel, C. F, Lillian B., \& Rui, M. V. (2004). Antioxidants in wild mushrooms. Instituto Politécnico de Bragança, Campus de Sta. Journal of Agriculture and Food Chemistry, 23, 1894-2845.

Jeong, S. C, Jeong, Y. T., \& Yang, B. K. (2010). White button mushroom (Agaricusbisporus) lowers blood glucose and cholesterol levels in diabetic and hypercholesterolemic rats. Nutrition Resource Journal, 30(1), 49-56. http://dx.doi.org/10.1016/j.nutres.2009.12.003

Lee, J, Lim, S, Kang, S-M., Min, S., \& Son, K. (2012). Saponin inhibits hepatitis C virus propagation by up-regulating suppressor of cytokine signaling 2. PLoS ONE, 7(6), e39366. http://dx.doi.org/10.1371/journal.pone.0039366

Liu, R. H. (2004). Potential synergy of phytochemicals in cancer prevention: mechanism of action. Journal of Nutrition, 134(12), 3479S-3485S.

Nijveldt, R. J., Nood, E, Hoorn, D. E. C., Boelens, P. G., Norren, K., \& Leeuwen, P. A. M. (2001). Flavonoids: a review of probable mechanisms of action and potential applications. American Journal of Clinical Nutrition, $74,418-425$.

Oboh, G., \& Shodehinde, S. A. (2009). Distribution of nutrients, polyphenols and antioxidant activities in the pilei and stipes of some commonly consumed edible mushrooms in Nigeria. Bulletin of the Chemical Society of Ethiopia, 23, 391-398. http://dx.doi.org/10.4314/bcse.v23i3.47663

Pathak, V. N., Yadav, N., \& Gaur, M. (1997). Mushroom Production and Processing Technology. Becham Research Institute, CA 91010.

Ramkumar, L., Ramanathan, T., \& Thirunavukkarasu, P. (2010). Antioxidant and radical scavenging activity of nine edible mushrooms extract. International Journal of Pharmacology, 6, 950-953. http://dx.doi.org/10.3923/ijp.2010.950.953

Roslin, J. T., \& Anupam, B. (2011). Terpenoids as potential chemopreventive and therapeutic agents in liver cancer.World Journal of Hepatolology, 3(9), 228-249. http://dx.doi.org/10.4254/wjh.v3.i9.228

Shiuan, C. (2004). Anticancer activities of white button mushrooms. Journal of Nutrition Bethesda, 134(12S), 3532S-3533S.

Siekmann, J. H., Allen, L. H., Bwibo, N. O., Demment, M. W., Murphy, S. P., \& Neumann, C. G. (2003). Prevalence of deficiency diseases in Kenya. Journal of Nutrition, 133(2S), 3972S-3980S.

Yu, S., Weaver, V., Martin, K., \& Cantorna, M. T. (2009). Effect of whole mushrooms during inflammation BMC Immunology Journal.

\section{Copyrights}

Copyright for this article is retained by the author(s), with first publication rights granted to the journal.

This is an open-access article distributed under the terms and conditions of the Creative Commons Attribution license (http://creativecommons.org/licenses/by/3.0/). 